\title{
Interactive comment on "Effects of Liquid-Liquid Phase Separation and Relative Humidity on the Heterogeneous OH Oxidation of Inorganic-Organic Aerosols: Insights from Methylglutaric Acid/Ammonium Sulfate Particles" by Hoi Ki Lam et al.
}

\section{Anonymous Referee \#2}

Received and published: 26 October 2020

General comments. The manuscript presents results from studies probing the effects of liquid-liquid phase separations on the loss rate for methylglutaric acid signal through heterogeneous $\mathrm{OH}$ oxidation. A range of different analyses were combined with the flow tube studies to fully characterize the system including optical microscopy, an electrodynamic balance, and modeling studies. The authors found that the heterogeneous $\mathrm{OH}$ oxidation rate increased in LLPS particles, likely due to increased organic concentrations near the surface in the particles. Overall the paper is well written and the 
conclusions are supported by the data. There are a few places where additional information would enable a broader view of the results. I recommend this manuscript for publication in ACP after the following minor comments are addressed.

\section{Specific Comments}

1. The effective heterogeneous $\mathrm{OH}$ rate constant was reported to vary from $1.01 \mathrm{x}$ $10^{\wedge}-12$ to $1.73 \times 10^{\wedge}-12 \mathrm{~cm}^{\wedge} 3$ molecule $-1 \mathrm{~s}^{\wedge}-1$. How does this scale to lifetimes in the atmosphere? How much of a difference might be expected for the lifetimes of organic compounds in LLPS systems in the atmosphere?

2. Where do the various error estimates come from? Are these from fits or from replicate measurements (or both)?

3. In the discussion of diffusivity, the comparison is made for laboratory studies. How would this extrapolate to temperatures found in the atmosphere? Could we still anticipate that diffusion would not be limiting, especially given the lower $\mathrm{OH}$ radical concentrations?

4. The kinetics were tracked by looking at the loss of the parent signal, and the same products appear to be formed in the experiments. However, the intensities of these products have some apparent differences in Figure S4. Was there any correlation of product ion signals to the decay rate of the parent ion? Either in terms of the relative intensities between $\mathrm{C} 6 \mathrm{H} 9 \mathrm{O} 5-$ or $\mathrm{C} 6 \mathrm{H} 7 \mathrm{O} 5$ - or the total product ion signal?

5. Figure 1 is not interpretable in black and white, I suggest a different color scheme, or more gradation.

6. What are the error bars on Figure 5 a (how are they estimated)? Are there error bars that can be applied to Figure $5 b$ ?

Interactive comment on Atmos. Chem. Phys. Discuss., https://doi.org/10.5194/acp-2020-900, 2020. 